
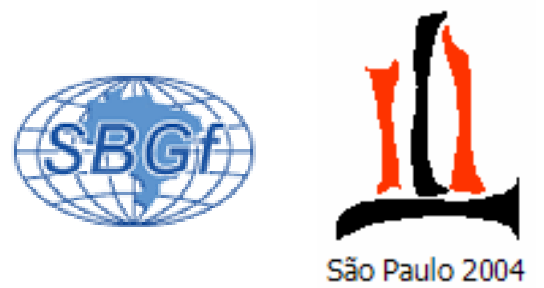

\title{
Fault permeability structure from reservoir induced seismicity (RIS) observations and 3D flow modeling in NE Brazil
}

Aderson F. do Nascimento (Universidade Federal do Rio Grande do Norte, Programa de Pós-Graduação em Geodinâmica e Geofísica, Natal, RN), Rebecca Lunn (School of the Built Environment, Heriot-Watt University, Edinburgh), Patience Cowie (Department of Geology and Geophysics, University of Edinburgh, Edinburgh)

Copyright 2004, SBGf - Sociedade Brasileira de Geofísica

Este texto foi preparado para a apresentação no I Simpósio de Geofísica da Sociedade Brasileira de Geofísica, São Paulo, 26-28 de setembro de 2004. Seu conteúdo foi revisado pela Comissão Tecno-científica do I SR-SBGf mas não necessariamente representa a opinião da SBGf ou de seus associados. E proibida a reprodução total ou parcial deste material para propósitos comerciais sem prévia autorização da SBGf.

\section{Abstract}

We use observations of RIS beneath Açu Reservoir, NE Brazil, to investigate the damage zone permeability of geological faults. High-resolution digital seismic monitoring of the reservoir has provided unusually detailed information on the locations of seismic events. The temporal distribution of these events shows them to be directly related to annual fluctuations in the reservoir level. Model simulations show that for pressure-diffusion to be a hydrogeologically consistent mechanism for RIS, preferential flow must occur within 2D fault planes embedded in a 3D low permeability matrix. The observed spatial and temporal variability of earthquakes indicate that these faults must have heterogeneous permeability fields with significant spatial structure; Our simulations indicate that $<0.05 \mathrm{kPa}$ of pressure change at hypocentral depth is required to trigger seismic events.

\section{Introduction}

Açu reservoir was constructed in 1983 and has a capacity of $2.4 \times 10^{9} \mathrm{~m}^{3}$ maintained by a $34 \mathrm{~m}$ high earth-filled dam constructed on Precambrian shield. Annual reservoir variation is 3-6 m which results in annual seismic activity due to a proposed mechanism of pore pressure diffusion (Ferreira et al. (1995), do Nascimento et al. (2004a)). Digital data at Açu have revealed the seismic activity in remarkable detail (do Nascimento et al. 2004a). The majority of earthquake activity is clustered within several well-defined zones and individual zones are active over discrete periods of time. In this paper we present the main features of the seismicity data and propose that the observed spatial and temporal evolution of seismicity at Açu is defined by pressure diffusion through local fault planes with heterogeneous permeability structures.

\section{Seismic activity at açu}

Induced seismic activity in the Açu area has been monitored over a ten year period from 1987-1997. (Figure 1) However, accurate hypocentral information is only available from 1994 to 1997, when a network of threecomponent digital seismographs were operational which have provided a very accurate assessment of hypocentral with errors of $\approx 100 \mathrm{~m}$ do Nascimento et al. 2004a.
Table 1. Activation periods of clusters recorded by the digital seismic network and permanent station BA1.

\begin{tabular}{lc}
\hline Period of activation & $\begin{array}{c}\text { Active seismic } \\
\text { cluster }\end{array}$ \\
\hline Nov. 1994 - 15/Aug./1995 & a, BA1 cluster \\
\hline 15/Aug./1995 - 21/Oct./1995 & a \\
\hline 21/Oct./1996 - 22/Nov./1996 & b \\
\hline 25/Nov./1996 - 30/Dec/1996 & c,b \\
\hline 30/Dec./1996 - May/1997 & a,b \\
\hline
\end{tabular}

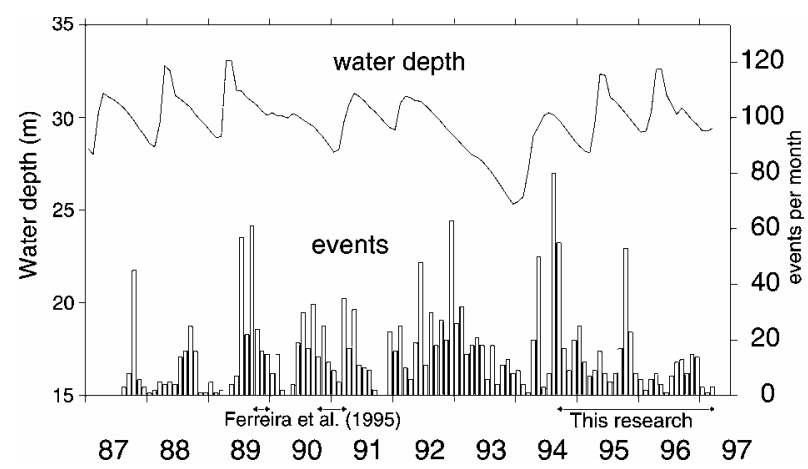

Figure 1: Monthly variation of reservoir water depth (top line) and monthly seismic activity (histograms) at Açu reservoir.

With such well located events provided by the digital monitoring it has been possible (do Nascimento et al. 2004a) to examine the relationship between the migration of events and the water level variation. Figure 2 shows three spatially identifiable seismic clusters, $\mathbf{a}, \mathbf{b}$ and $\mathbf{c}$ that are separated both temporally and spatially (vertical sections from the projection lines shown on Figure 2 showed the clusters to be on separate fault planes). Table 1 summarises the temporal evolution of each cluster. A more detailed picture of their temporal evolution is shown in Figure 3. Here, the evolution of each of the clusters is shown simultaneously by plotting the depth of each event against the time delay calculated from the previous reservoir level peak. Three observations are apparent from Figures 1-3 and Table 1 that are obviously consistent with a mechanism for RIS of pressure diffusion:

(i) The onset of peak seismicity is delayed with increasing depth of cluster (Table 1, Figure 3)

(ii) The duration of seismic activity reduces with depth of cluster: this is consistent with the amplitude of the pressure wave decreasing with depth, causing a reduction in the time that the pressure exceeds a given value (Figure 3). 
(iii) There is an apparent cessation in seismic activity during the 1993 drought (Figure 1).

However, three further observations that are not immediately consistent with this mechanism:

(iv) The average speed of propagation of the pressure wave differs between clusters; for clusters $\mathbf{a}$ and $\mathbf{b}$ it is $\approx 15 \mathrm{~m} /$ day and for cluster $\mathbf{c} \approx 21 \mathrm{~m} /$ day (calculated from Table 1).

(v) Each cluster shows a rapid onset to peak seismicity followed by a long tail with gradually diminishing event frequency (Figure 3).

(vi) There is no apparent relationship between temporal within-cluster evolution and depth: for pressure diffusion in a homogeneous medium within-cluster events should get gradually deeper over time (Figure 3).

Next, we demonstrate that pressure-diffusion is a hydrogeologically valid mechanism for RIS at Açu as supported by observations (i)-(iii), and that the seemingly inconsistent observations of seismicity (iv)-(vi) can be explained by flow within faults with spatially structured heterogeneous permeability fields.

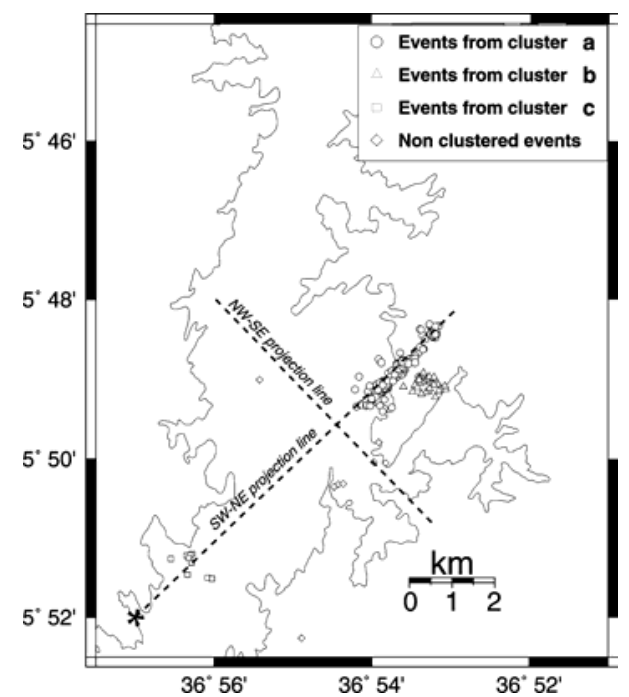

Figure 2: The epicentres located by the digital network in map view.

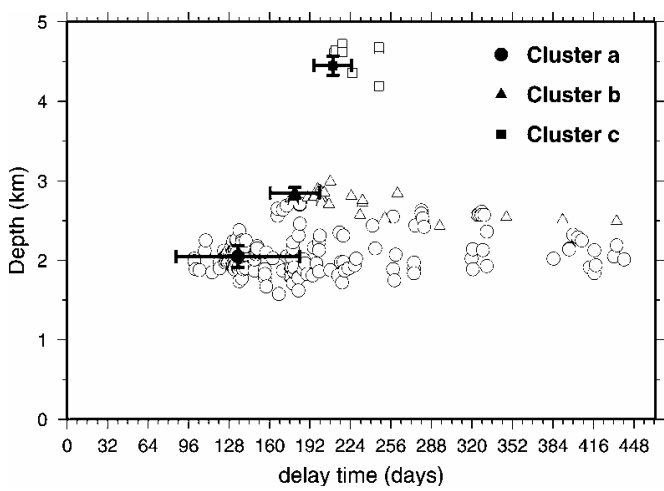

Figure 3: Time delay from the previous reservoir peak plotted against depth for clusters $a, b$, and $c$. The filled symbols denote the modal average delay time, error bars show the interquartile range.

\section{D flow modelling}

To assess the hydrogeological feasibility of pressure diffusion as a mechanism for RIS at Açu, it is first necessary to construct a numerical model of induced seismicity. Several previous authors including Roeloffs (1988) and Kalpna (2000) have modelled RIS employing a range of different modelling assumptions including: the level of hydromechanical coupling; the representation of rock properties; and the model geometry. Kalpna (2000) is the only previous author to model RIS in 3D. He uses a Green's function approach that requires a homogeneous subsurface permeability field. At Açu, we specifically wish to investigate the effect of heterogeneous permeability fields, so a new model is required. Since the data show no obvious undrained mechanism for RIS (Figure 1), we have adopted the simplest available approach of assuming an exponential decrease in permeability due to crack closure in response to increased confining pressure at depth.

To model pressure diffusion at Açu, the threedimensional groundwater flow code, PARADIGM (Lunn and Mackay 1997) is used. PARADIGM models flow within a $3 D$ rock matrix with embedded $2 D$ planar faults. Faults have a separate 2D planar mesh and can be at any location and orientation: interaction with the 3D matrix mesh is provided by a fully implicit flow solution that allows leakage between fault nodes and the nearest matrix nodes. Further details of PARADIGM and its application at Açu are presented in Nascimento et al. (2004b).

Development of a realistic conceptual model of groundwater flow beneath Açu requires accurate information on boundary and initial conditions for the seismically active area. Very few hydrological data sets were available for the Açu region. However, two conclusions could be drawn: the xerophilous vegetation and the observations that surface water features are topographically higher than the surrounding water table (inferred from stream gauging data and xerophilous vegetation below dam). Therefore, we concluded that there is no groundwater recharge at the upper boundary and flow from surface water features is outwards (leaking into groundwater).

The upper boundary in the model is represented as a sinusoidally oscillating reservoir level whereby nodes within the reservoir at any given time are assigned a fixed head. The reservoir boundary itself varies according to the topographic data as the water level rises and falls. Lateral boundary conditions for the seismically active region are not possible to assess from data, therefore, an approach of using a regional scale model to provide boundary conditions for a finer scale local model has been adopted. A detailed description of the modelling approach taken is given in Nascimento et al (2002b).

\section{Model calibration and results}

Two conceptual models of groundwater flow beneath Açu have been simulated using PARADIGM. In the first case, the matrix model, pressure diffusion is within a $3 D$ 
homogeneous matrix and the diffusion coefficient, $D$, is calibrated such that the peak pressure reaches $2 \mathrm{~km}$ depth after 4.5 months. This time delay matches the observed delay in peak seismicity for cluster a, which has the most events. In the second case, the fault model, the same matrix mesh is employed, but with the addition of a single 2-D embedded planar fault. The orientation and dip of the fault have been estimated from the seismic location data for cluster a. The matrix permeability is held constant at a typical value for intact crystalline rock and the fault diffusivity is calibrated to match the observed 4.5 month time delay of the pressure wave to $2 \mathrm{~km}$ depth.

Only the fault model, fault model produces physically consistent hydraulic parameters and demonstrates that pressure-diffusion through a permeable fault plane embedded in a low permeability matrix is a hydrogeologically valid model for RIS at Açu (see do Nascimento et al., 2004c).

\section{Explaining the spatio-temporal variability of earthquakes}

The RIS observations in Açu reservoir (Section 2) are not immediately consistent with the above model of pressurediffusion at Açu. In each case, we will show that these can be explained by the presence of heterogeneous subsurface permeability structures. The first of these observations (iv - Section 2) is that the average speed of propagation of the pressure wave differs between clusters. Analysis of the data in Figure 2 and other vertical projections clearly show that the clusters are on different fault planes. Therefore, the differing speeds of propagation must be caused by different mean transmissivity values on the individual fault planes.

The remaining two observations (v) and (vi) relate to the spatial and temporal variability of earthquake evolution within individual clusters. In the following sections, we investigate the hypothesis that this variability is consistent with pressure diffusion within faults that contain a spatially structured heterogeneous transmissivity field. Detailed results from these investigations at Açu are presented in Nascimento et al (2004c).

\section{Fault heterogeneity}

Field and microstructural studies of fault zones (e.g. Caine et al. (1996)) have shown them to be composed of two distinct compartments: a fault core and a damage zone. This two compartment structure results in heterogeneity of hydraulic conductivity in the plane, due to both the existence of the low permeability core and the heterogeneous nature of the fractured damage zone. Caine (1996) also presented a conceptual scheme for fault-related fluid flow. According to the proportion of damage zone to the proportion of fault core, they defined four end-member architectural styles, each associated with a characteristic hydraulic conductivity structure: (1) localised conduits, (2) distributed conduits, (3) localised barriers and (4) combined conduit-barriers. Field observations of the faults in the Açu region show them to be typically characterised by zones of intense fracturing that demonstrate both opening and minor shear offsets. In terms of fluid flow, they are best described as distributed conduits in which the permeability is dominated by a fractured damage zone

To incorporate heterogeneity in the pressure diffusion model a spatially varying transmissivity field is introduced within the fault plane. Fault transmissivity is log-normally distributed and is described by a spatially correlated random field with an exponential covariance structure. Mean fault permeability is significantly greater than that within the rock matrix to maintain the conceptual model of preferential flow within a $2 \mathrm{D}$ fault plane embedded in a $3 D$ rock matrix. The effect of increasing compressive stress with depth is incorporated in both the matrix and fault by applying an exponential reduction in permeability with depth. In the case of the fault, this is achieved by first generating the log-normal spatially correlated field and then applying the exponential transformation. Figure 4 shows the resulting transmissivity fields within the fault plane for two different statistical parameter sets: a correlation length of $167 \mathrm{~m}$ with a variance for $\log T_{f}$ of 0.25 ; a correlation length of $500 \mathrm{~m}$ with a variance for $\log T_{f}$ of 0.5 . As expected, the right hand field demonstrates more spatial structure with a greater range of log transmissivity values; patches of low and high permeability are 1-1.5 km across. In our simulations, we included the reduction in transmissivity due to increasing compressive stress.

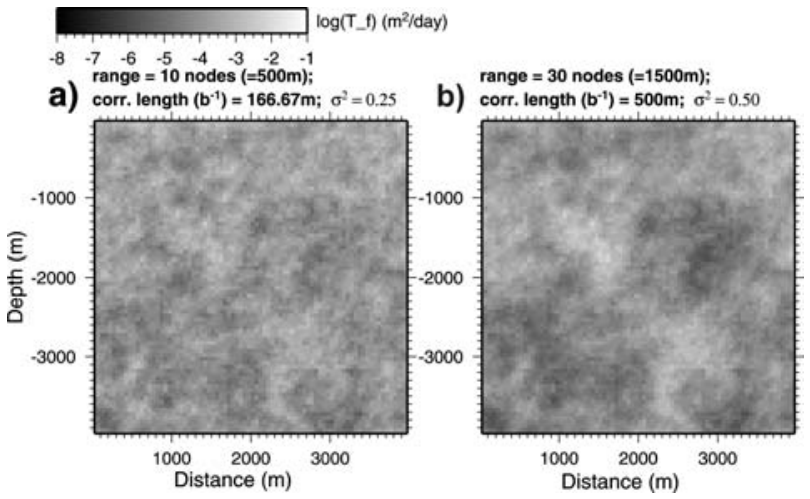

Figure 4: Fault transmissivity fields for two different values of the correlation length and variance

\section{Simulation of earthquake evolution}

Pressure diffusion was simulated for a number of statistical parameter sets. Due to the small number of realisations it is only possible to see how changes in statistics are influencing earthquake evolution (but not to derive accurate population statistics).

To compare simulation results with the observation data, it was assumed that earthquakes occur at the time of maximum pressure increase at a given depth. The simulations were compared using 3 statistics derived from both the observation data and the model predictions: the median time delay from reservoir peak; the interquartile range (IQR); and the range. The results of these simulations in the $1800-2200 m$ depth range are given in Table 2; for the model predictions, values are ensemble statistics for the 5 realisations. More detailed simulation results, including additional depth ranges are presented in do Nascimento et al. (2002c). 
Table 2. The correlaion length, $C_{l}$, and variance of $\log T_{f}$, $\sigma^{2}$, derived from the observation data and model predictions.

\begin{tabular}{lccc}
\hline $\begin{array}{l}\text { Delay time: } \\
\text { 1800-2200m }\end{array}$ & $\begin{array}{c}\text { Median } \\
\text { (days) }\end{array}$ & $\begin{array}{c}\text { IQR } \\
\text { (days) }\end{array}$ & $\begin{array}{c}\text { Range } \\
\text { (days) }\end{array}$ \\
\hline Observation data & 149 & 68 & 359 \\
\hline$C_{l}=0 \mathrm{~m} \sigma^{2}=0.5$ & 136 & 16 & 56 \\
\hline$C_{l}=167 \mathrm{~m} \sigma^{2}=0.25$ & 120 & 32 & 96 \\
\hline$C_{l}=167 \mathrm{~m} \sigma^{2}=0.5$ & 120 & 48 & 120 \\
\hline$C_{l}=500 \mathrm{~m} \sigma^{2}=0.25$ & 120 & 40 & 160 \\
\hline$C_{l}=500 \mathrm{~m} \sigma^{2}=0.5$ & 120 & 48 & 224 \\
\hline
\end{tabular}

Table 2, column 2, shows that the median time delay does not vary significantly between transmissivity fields. This is explained by the fact that the mean transmissivity profile (exponentially decaying over depth) has been calibrated, prior to the introduction of any random variation, to achieve the observed 4.5 month delay for cluster a at $2 \mathrm{~km}$ depth.
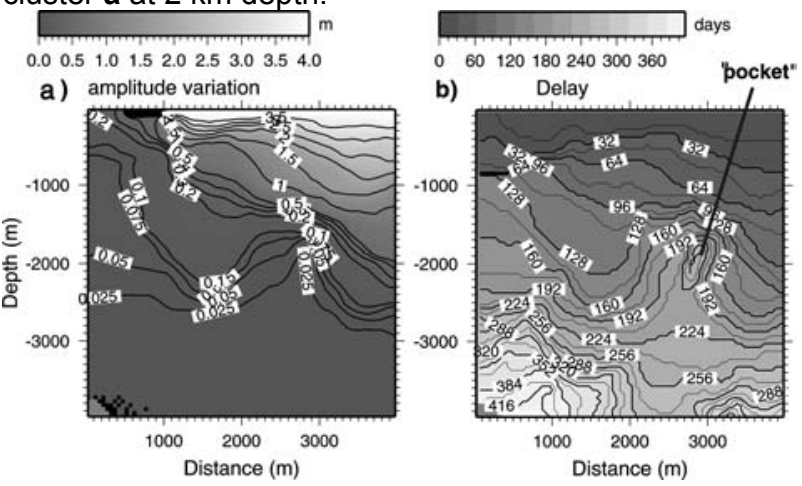

Figure 5: Contours of maximum (a) pressure change and (b) time delay from reservoir peak for the transmissivity field in Figure 4(b).

Columns 3 and 4 of Table 2 show the IQR and range, in each case the observation data are higher than those derived from the ensemble statistics. However, large variations are apparent across the different statistical parameter sets. In general, the IQR and range are increasing with increases in correlation length and variance of log transmissivity. In addition, the observation data themselves represent a single statistical realisation and an analysis of the individual realisations for a correlation length of $500 \mathrm{~m}$ and a variance of 0.5 shows that even with only 5 realisations the IQR varies between 28 to 56 . Hence, it seems likely that further simulations could reproduce the observed value of 68 .

Since the observation data represent pressurediffusion in a single realisation of fault transmissivity, it is interesting to compare in more detail the observation data and simulation results from an individual transmissivity field. Figure 5 shows contour plots of the maximum pressure change within the fault plane and the time delay from reservoir peak for an individual realisation from the final parameter set in Table 2. Figure 5(a) shows that seismic events are predicted to occur due to a maximum pressure change of $0.5 \mathrm{kPa}$ (equivalent to $<0.05 \mathrm{~m}$ of head), hence the fault must be very close to failure.
Analysis of Figure 5(b) shows that the high correlation length is leading to the presence of 'pockets' of long time delay; these are observed in all 5 five realisations and are not present in predictions from any of the other parameter sets

\section{CONCLUSIONS}

A conceptual and numerical model of fluid flow beneath Açu reservoir has been developed to model RIS. Model simulations show that for pressure-diffusion to be a hydrogeologically consistent mechanism for RIS, with preferential flow occuring within 2D fault planes embedded in a 3D low permeability matrix. The observed spatio-temporal variability of earthquakes at Açu indicate that these faults must have heterogeneous permeability fields with significant spatial structure; pockets of high and low permeability of the order of $0.5-1.5 \mathrm{~km}$ in diameter. Predictions of the maximum pressure change in the faults at hypocentral depths, indicate that only small changes in the effective stress field $<0.05 \mathrm{kPa}$ trigger seismic events.

\section{REFERENCES}

do Nascimento, A.F., Cowie, P.A. Lunn, R.J. \& Pearce R.G. 2004a. Spatio-temporal evolution of induced seismicity at Açu reservoir, NE Brazil. Geophys. J. Int. (in press).

do Nascimento, A.F., Lunn, R.J. \& Cowie, P.A. 2004b. Numerical modelling of pore pressure diffusion in a reservoir-induced seismicity site in NE Brazil. Geophys. J. Int. (in press).

do Nascimento, A.F., Lunn, R.J. \& Cowie, P.A. 2004c. Modelling the heterogeneous hydraulic properties of faults using constraints from Reservoir Induced Seismicity. Geophys. J. Int. (in press).

Ferreira, J.M., Olivera, R.T., Assumpção, M., Moreira, J.A.M., Pearce, R.G. \& Takeya, M.K. 1995. Correlation of seismicity and water level - an example from northeastern Brazil. Bull. Seismol. Soc. Am. 85: pp1483-1489.

Roeloffs E.A. 1988. Fault stability changes induced beneath a reservoir with cyclical variations in water level. J. Geophys. Res. 93(B3): pp2107-2124.

Kalpna R.C. 2000. Green's function based stress diffusion solutions in the porous elastic half space for time varying finite reservoir loads. Phys. Earth Planet. Int. 120: pp93-101.

Caine, J.S., Evans, J.P., \& Forster, C.B. 1996. Fault zone architecture and permeability structure. Geology 24(11): pp1025-1028.

\section{ACKNOWLEDGEMENTS}

AFDN was supported by CNPq, ANP, CTPETRO and FINEP (Brazil). PC was supported by a University Research Fellowship from the Royal Society of London. 